\title{
Environmental information usefulness to stakeholders: empirical evidence from Malaysia
}

\begin{abstract}
Purpose: The present study aims to examine the effect of environmental information on fund managersôinvestment and bank officersôlending decisions. Specifically, it looks at the effect of qualitative and quantitative forms of environmental information to their decisions.

Design/methodology/approach: Drawing from the normative pressure of institutional theory, the study seeks to identify the extent to which education and professional networks influence investment and lending decisions of fund managers and bank officers. A laboratory experiment was used to collect the data. Twenty-three subjects volunteered in each experimental group, totalling 69 responses from fund managers and bank officers. The subjects were Master of Administration (MBA) students in universities located in Selangor and Kuala Lumpur, Malaysia, to proxy for real practitioners.

Findings: The results reveal that fund managers and bank officers do not incorporate environmental information in their investment and lending decisions. Thus, the normative pressure of institutional theory is supported.

Research limitations/implications: Acknowledging the limitations of data generalisability using student surrogates, future research utilising real practitioners is proposed.

Practical implications: Recognising the importance of environmental information to be incorporated in investment and lending decisions of these major stakeholders, the results suggest universities, professional bodies and companies need to raise awareness concerning the importance and relevance of environmental information in various decisions.

Originality/value: The study offers some preliminary insights into the use of environmental information by fund managers and bank officers in Malaysia.
\end{abstract}

Keyword: Bank officer; Environmental information; Fund manager; Laboratory experiment; Malaysia 